\title{
A Unique Birth Control Vaccine under Development
}

\author{
Talwar GP'* Jagdish C Gupta ${ }^{1}$ and Shilpi Purswani ${ }^{2}$ \\ ${ }^{1}$ Talwar Research Foundation, India \\ ${ }^{2}$ Alpha Diagnostic International Inc, USA \\ *Corresponding author: Talwar GP, Talwar Research Foundation, E-8, Neb Valley, New Delhi-110068, India.

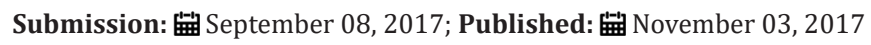

\begin{abstract}
Summarized here is the long journey traversed for development of a vaccine against human chorionic gonadotropin (hCG), which is safe, reversible and competent to prevent pregnancy in sexually active women without derangement of ovulation, reproductive hormones profile and menstrual regularity. A recombinant version of hCG $\beta$ linked to B subunit of heat-labile enterotoxin of E. coli, has been made and passed on to Industry for production under GMP conditions. The vaccine has received the approval of RCGM (Review Committee on Genetic Manipulation) and of the Drugs Controller General of India for clinical trials under the aegis of Indian Council of Medical Research.
\end{abstract}

\section{Introduction}

Reproduction is made possible by fertilisation of the ovum generated each month by a physiologically normal female by sperm contributed by her partner. Although in vitro fertilization (IVF) is feasible, in most cases this process occurs by an enjoyable intercourse. The fertilized egg develops to the blastocyst stage (whether after in vitro or in vivo fertilization) when it is ready for implantation onto a receptive endometrium which leads to pregnancy. In this process, human chorionic gonadotropin (hCG), a hormone produced by the growing embryo plays a critical role. We developed a vaccine against hCG, which has the ability to generate antibodies competent to intercept this process and thereby prevent the onset of pregnancy. This article will briefly review this work and report its current status.

The choice of hCG as a 'target' was based on two considerations:

a) The fact that this molecule is not produced normally by any organ of a healthy non-pregnant female, and thus the antibodies against it would not produce side-effects.

b) That hCG plays a key role in implantation and hence antibodies competent to neutralize its bioactivity would block the key step leading to pregnancy without affecting the normal female functions of ovulation, production of hormones and periodicity of menstruation.

\section{Design of the Vaccine}

hCG is composed of 2 subunits, alpha and beta linked to each other non-covalently [1]. Figure 1 shows the structure of these hormonal subunits.

Alpha subunit of hCG is common to 3 other pituitary hormones, namely FSH, LH and TSH. It is the beta subunit of each hormone that gives them the individual character. Hence we decided to employ $\beta$ subunit of hCG as antigen in the vaccine. The beta subunit however is a "self" molecule and the body would not produce antibodies against it. It was made immunogenic by linking it to a carrier tetanus toxoid (TT). TT is used world-wide for immunization to prevent tetanus. It is a cheap vaccine, available in plenty commercially. $\beta$ hCG-TT conjugate did generate antibodies against both hCG and tetanus, not only in experimental animals but also in women (Figure 2). The initial trial was conducted in 4 women. They had completed their families and got themselves tubectomized to prevent further pregnancies.

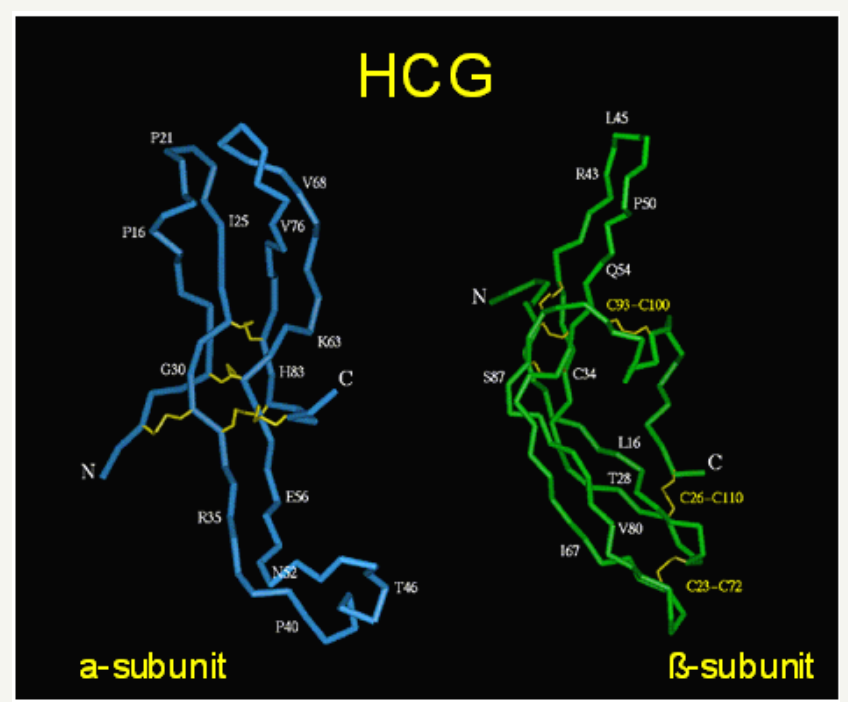

Figure 1: $a$ and $\beta$ subunits of hCG molecule. Alpha (a) Subunit is common to 3 other pituitary hormones: TSH, LH and FSH. Beta ( $\beta$ ) Subunit is hormone specific. 


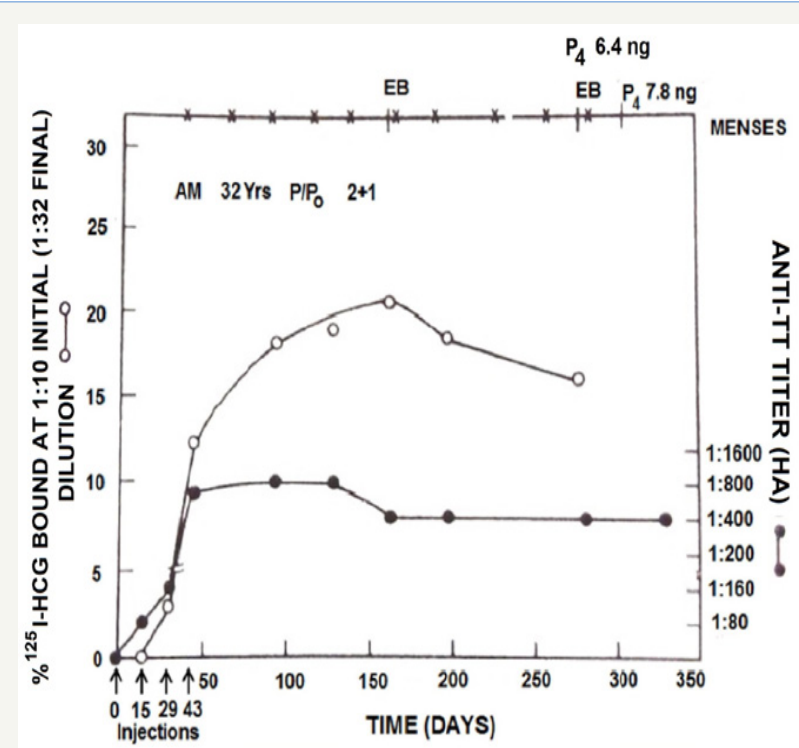

Figure 2: Anti-hCG and anti-tetanus antibody response to hCG $\beta$-TT in a 32 year old fertile woman AM, who had two children and one MTP [1].

Antibodies were generated against both hCG and tetanus. Injection of a load dose of hCG bound to anti-hCG antibodies, bringing down their titres without influencing antibodies against tetanus. The anti-hCG titres returned to the previous level in course of time. The anti-tetanus antibodies remained at the same level indicating that the vaccine generated independent antibodies against both hCG and tetanus. Figure 3 shows the kinetics of antihCG antibodies in 2 subjects enrolled in this study. Immunization with hCG $\beta$-TT vaccine was fully safe and devoid of any side-effects $[2,3]$. In all 4 women, the antibody response was reversible and the antibody titres declined to zero level in course of time.

\section{Enhancement of Immunogenicity}

While linkage of hCG $\beta$ to a carrier (TT) did make it immunogenic in women, the titres of antibodies induced were low and insufficient to neutralize the hCG that is formed at the early stages of pregnancy. Strong and oily adjuvants, if used, would entail side-effects deterring potential recipients to get vaccinated. One had to enhance the intrinsic immunogenicity of the vaccine employing permissible, easily tolerated adjuvants. We considered associating the $\beta$ subunit of hCG with $\alpha$ subunit of ovine LH, which being a non-self molecule is expected to be intrinsically immunogenic in humans. The ability of $\alpha$ and $\beta$ subunits to associate with each other non-covalently is preserved across the species. The hetero-species-dimer (HSD) of hCG $\beta$ with $\alpha \mathrm{oLH}$, was indeed more immunogenic and generated better neutralizing hCG antibodies. Table 1 summarises some of the findings. The procedures followed are reported elsewhere [4].

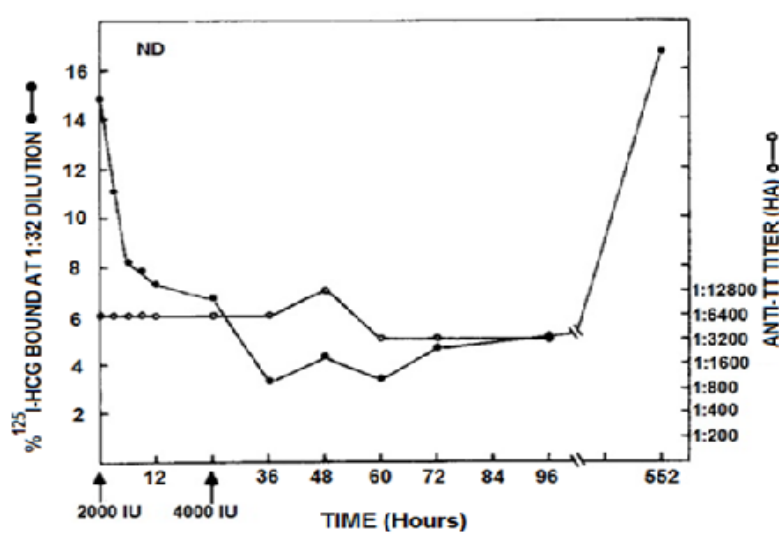

Figure 3: Evidence of the ability of antibodies to bind with hCG [2].

Table 1: hCG binding and neutralization capacity of anti- $\beta$ hCGTT or $\beta$ hCG-cholera toxin B subunit (CHB) and anti-HSD-TT antisera generated in bonnet monkeys and rats (4).

\begin{tabular}{|c|c|c|c|c|}
\hline Immunogen & $\begin{array}{c}\text { No. of } \\
\text { animals }\end{array}$ & $\begin{array}{c}\text { hCG } \\
\text { binding } \\
\text { capacity } \\
\text { (pg/ml) (I) }\end{array}$ & $\begin{array}{c}\text { hCG } \\
\text { neutralization } \\
\text { capacity (pg/ } \\
\text { ml) (B) }\end{array}$ & B/Ix100 \\
\hline $\begin{array}{c}\text { Bonnet } \\
\text { Monkeys }\end{array}$ & & & & \\
\hline$\beta$ hCG-TT/CHB & 5 & $22.2 \pm 2.3$ & $10.1 \pm 1.8$ & $44 \pm 3.7$ \\
HSD-TT/CHB & 5 & $21.4 \pm 1.9$ & $14.0 \pm 1.4$ & $65 \pm 1.9$ \\
\hline Rats & & & & \\
\hline$\beta$ hCG-TT/CHB & 6 & $27.1 \pm 1.7$ & $17.1 \pm 1.2$ & $63 \pm 1.5$ \\
HSD-TT/CHB & 6 & $32.5 \pm 1.4$ & $26.1 \pm 0.8$ & $80 \pm 2.3$ \\
\hline
\end{tabular}

The next obvious question was whether this vaccine indeed prevented pregnancy in fertile women. For this Phase II trials were necessary which were conducted after obtaining permission of the Drugs Controller General of India (DCGI) and Institutional Ethics Committees.

\section{Efficacy of the vaccine to prevent pregnancy}

Phase II clinical trials were conducted in three centres in India: the All India Institute of Medical Sciences New Delhi, Postgraduate Institute of Medical Education \& Research Chandigarh and Safdarjung Hospital New Delhi. Women of reproductive age with 2 living children who had active marital life with frequent intercourses were enrolled for the trial by written consent. All of them had regular menstrual cycles. Luteal phase Progestronede terminations indicated that they were ovulating regularly. The enrolled women were immunized with $300 \mu \mathrm{g}$ of HSD-TT vaccine. A course of 3 
primary injections at 15 or 30 day interval was necessary to lead to the induction of antibodies. Thereafter booster injections were given as and when the antibodies declined. A putative threshold of antibodies at and above $50 \mathrm{ng} / \mathrm{ml}$ bio neutralization capacity of hCG was fixed to see whether at these antibody titres and above, she was protected from becoming pregnant.
A total of 148 women were enrolled for this trial. While all of them generated antibodies against $\mathrm{hCG}$ after vaccination, however 110 of them had titres above the presumed protective threshold of $50 \mathrm{ng} / \mathrm{ml}$ for at least 3 months or longer. Figure 4 shows the findings in 4 women [5].
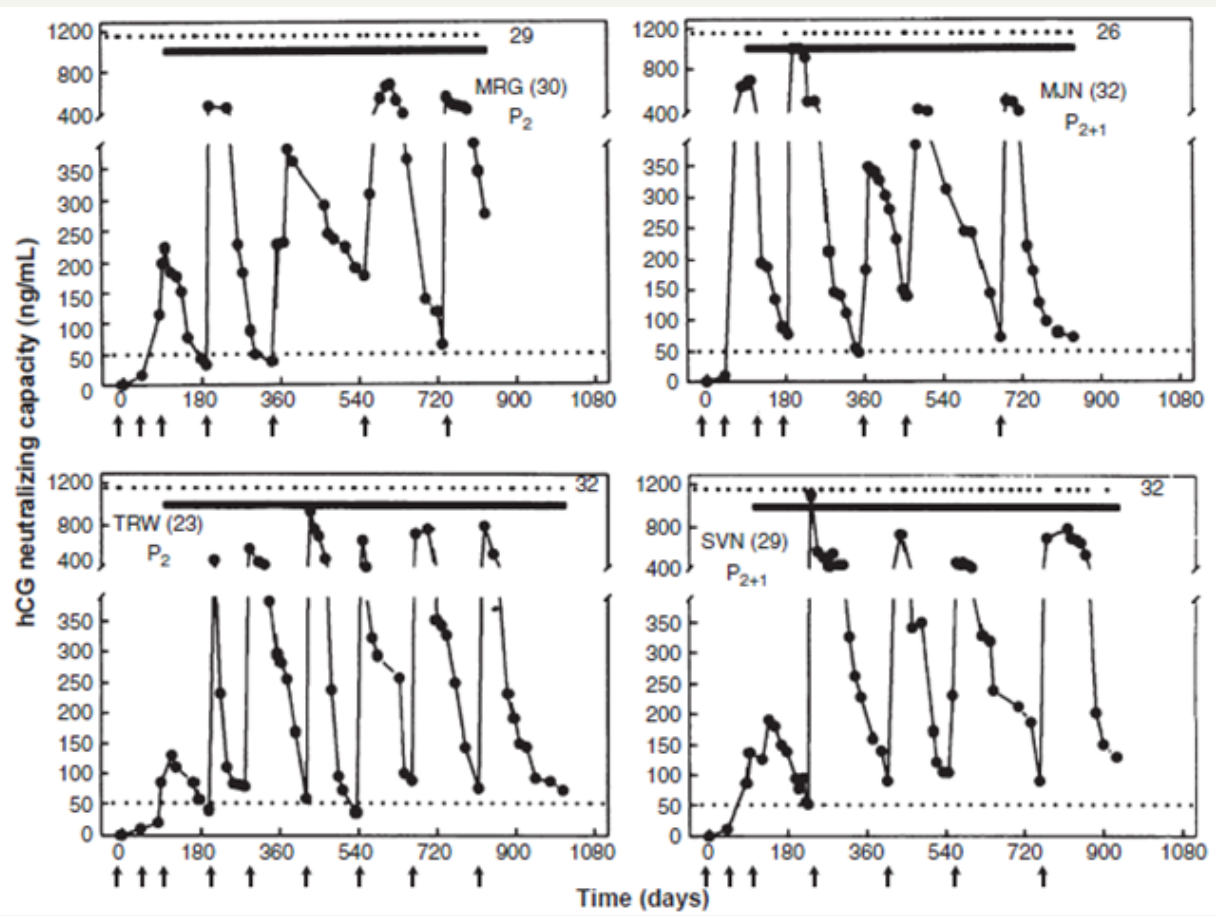

Figure 4: Anti-hCG response to the HSD vaccine in 4 sexually active women of proven fertility. MRG 30 year old and TRW 23 year old had 2 children each; HJN 32yr \& SVN 29 year old had 2 children each and 1 elective termination of pregnancy. All of them remained protected from becoming pregnant over 26-32 cycles, at top edge are represented the menstrual events which remained regular, solid lines denote the period over which they were exposed to pregnancy. Arrows indicate the day on which vaccine was given. Booster injections were given to keep antibody titres above 50ng/ $\mathrm{ml}$ [5].

The vaccine was highly effective in preventing pregnancy. Only one pregnancy occurred in 1224 cycles. All women kept ovulating normally and had regular menstrual cycles. Eight women were protected for 30 cycles without becoming pregnant, nine were protected over 24-29 cycles, 15 for 12-17 cycles and 21 for 6-11 cycles. Thus the vaccine had high efficacy. What is more, contraception was achieved without derangement of menstrual regularity and hormonal profiles. In this respect, it was a unique vaccine for Birth Control.

\section{Reversibility and regain of fertility}

While antibodies declined in course of time to near zero level in all women in the absence of boosters, one had to determine whether previously immunized women regain fertility. Luckily 4 women in the cohort undergoing the trial, desired to have another child, and did not take booster injections. All 4 of them conceived and carried to term their pregnancy. Figure 5 gives the antibody response in one of these women, who remained protected for nearly one year after 3 primary injections and a booster. She conceived in the first cycle, when her antibody titres declined below $20 \mathrm{ng} / \mathrm{ml}$. She gave birth to a normal child.

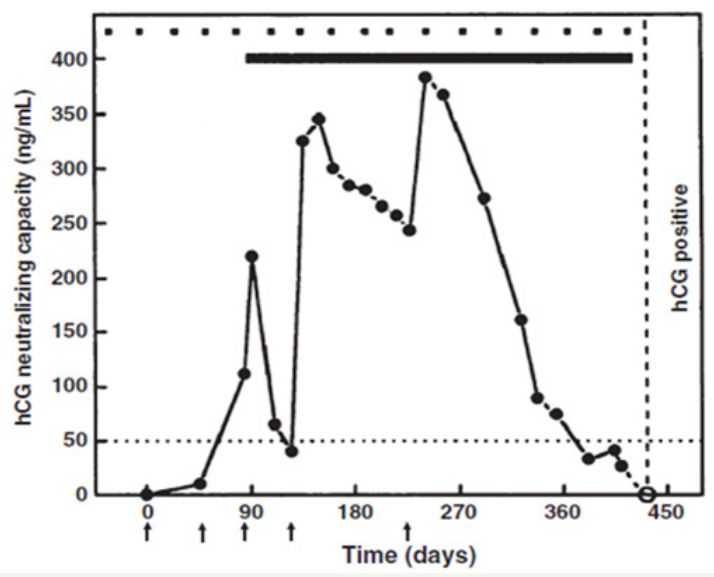

Figure 5: Regain of fertility on decline of antibodies. A 30-year-old subject (STS), with two gravidae and one elective abortion $(\mathrm{P} 2+1)$, on immunization with the vaccine, remained protected from pregnancy for 12 cycles. In the absence of a booster injection, antibody titers declined and she became pregnant in the cycle starting on day 417 . The extrapolated antibody titers at mid cycle in the fertile month, shown by the dotted line, were $<5 \mathrm{ng} / \mathrm{ml}$. Arrows indicate the day on which vaccine was given [5]. 


\section{Normalcy of children born to women on decline of antibody titres}

Prof. Meharban Singh at the All India Institute of Medical Sciences, New Delhi, examined thoroughly the 4 children born to women previously immunized with the HSD-TT vaccine. Their developmental landmarks and cognitive abilities were normal and comparable to their siblings [6].

To sum up, the vaccine linking hCG $\beta$ subunit to a carrier engendering antibodies against hCG prevented unwanted pregnancy in women without blocking their ovulation and derangement of menstrual regularity. The effect of the vaccine was fully reversible. On decline of antibodies in the absence of a booster, women conceive after decline of antibodies to below $30 \mathrm{ng} / \mathrm{ml}$. The progeny born is normal as per the developmental landmarks and cognitive abilities of their siblings.

\section{Time Gap and revival of the vaccine}

I retired from the Directorship of the National Institute of Immunology (NII), New Delhi, in 1994. My successor requested me to leave the vaccine at the Institute which I created and of which I was the Founder Director. How could I refuse it? Nothing was done till 2006, when an Indo-US Committee on Contraception Research contacted me to revive the vaccine. I decided to make a genetically engineered recombinant vaccine, which could be amenable to industrial scale production. The $\beta$-subunit of hCG was linked to $B$ subunit of heat-labile enterotoxin (LTB) of Escherichia coli as carrier, and expressed as recombinant protein in yeast Pichiapastoris.

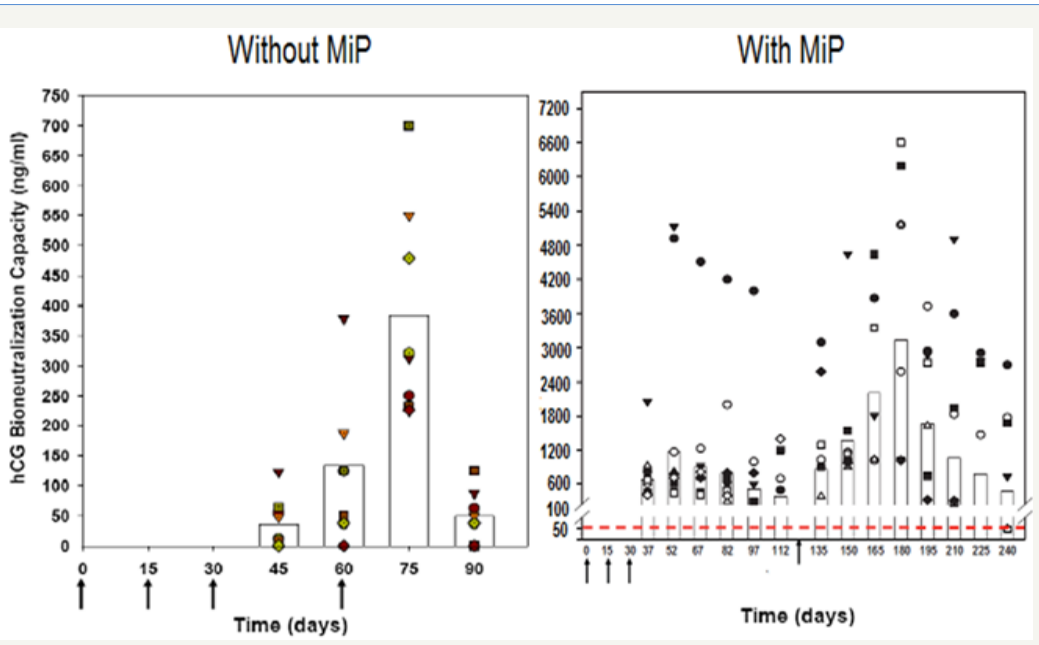

Figure 6: Enhancement of antibody response to hCG $\beta$-LTB vaccine in Balb/c mice by MIP. Mice were immunized intra-muscularly with $2 \mu \mathrm{g}$ of the vaccine adsorbed on alum with or without MIP. Primary immunization consisted of 3 injections given at fortnightly intervals followed by a booster on day 60 or 120 . The symbols represent the titres in a given mouse. Bars give the geometrical Means [7].

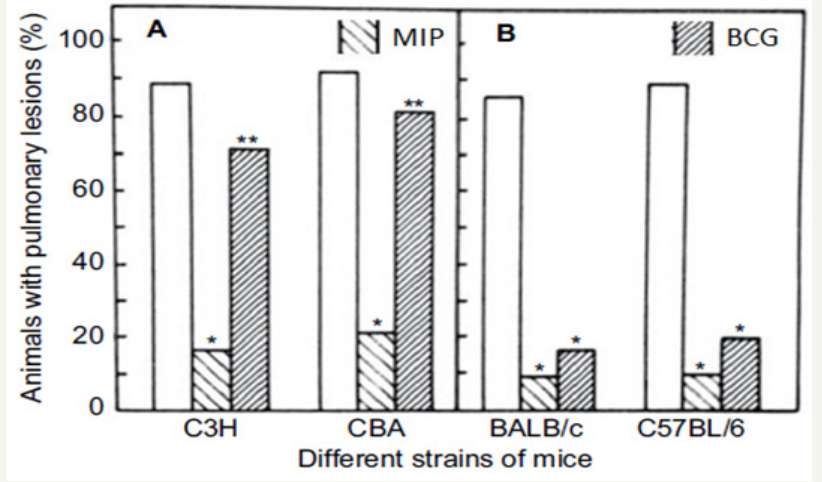

Figure 7: Effect of immunization with heat-killed MIP or live BCG on development of pulmonary lesions in $\mathrm{C} 3 \mathrm{H}$, CBA (Panel A) and in Balb/c, C57BL/6 (Panel B) strains of mice. Animals were immunized either with 107 heat-killed MIPs.c. or 104 live BCG i.v. Four weeks later, the animals were challenged with $107 \mathrm{M}$. tuberculosis H37Rvi.v. Four weeks post challenge, the animals were killed and visible lesions in the lungs were recorded. The data plotted are the mean of results obtained from three sets of experiments with MIP and two sets of experiments with BCG, with $\mathrm{n}=7$ 10 animals per group. The data for the non-immunized group of animals are also presented [10].
hCG $\beta$-LTB vaccine adsorbed on alhydrogel was immunogenic and generated bioneutralizing anti-hCG antibodies in Balb C mice. Its immunogenicity was considerably enhanced by inclusion of an adjuvant, heat-killed Mycobacterium indicus pranii (MIP) (Figure 6) [7]. MIP is a non-pathogenic atypical mycobacteria, which I had developed as an immunoprophylactic cum immune-therapeutic vaccine against leprosy [8]. It is approved by the DCGI and USFDA. Besides leprosy, it is effective as adjunct to standard drugs in treatment of Category II "Difficult to treat" tuberculosis [9]. MIP is superior to BCG, as it is active in both live and heat-killed form. Unlike BCG, it has no genetic restriction (Figure 7).

\section{Approvals of hCG $\beta$-LTB vaccine}

All genetically engineered products have to receive the approval of the National level Review Committee on Genetic Manipulation (RCGM) before these are considered for human use. The committee desired extensive toxicology studies to be carried out on this vaccine by a GLP company employing International Protocols. Preclinical toxicology studies were carried out in 2 species of rodents by $\mathrm{M} / \mathrm{s}$ Bioneeds at their GLP Facility in Bangalore India. Vaccine was fully safe by all criteria and also free of mutagenicity with no sensitization of skin. Safety and immunogenicity studies on the 
recombinanthCG $\beta$-LTB vaccine were also conducted in a subhuman primate species, the marmosets, at the National Institute of Research in Reproduction (NIRRH), Mumbai. Vaccine was found fully safe. Marmosets offered an additional opportunity to test the efficacy of antibodies in preventing pregnancy. 8/9 immunized marmosets were protected from becoming pregnant on co-habitation with fertile males, whereas all non-immunized marmosets in the control group became pregnant. On the basis of these findings, the vaccine received approval of RCGM, who recommended to DCGI to grant approval for going back to human trials.

\section{Current Status}

The approval of DCGI for conducting Phase I/II safety and efficacy trials has been received. The trial will be conducted under the aegis of the Indian Council of Medical Research. Also technology for making the vaccine has been transferred to a Biotech Company, who will make the vaccine under GMP conditions and supply it free of charge for the trial.

\section{Acknowledgement}

The work received research grants from the Department of Biotechnology, Govt of India and the Indian Council of Medical Research, New Delhi.

\section{References}

1. Lapthorn AJ, Harris DC, Littlejohn A, Lustbader JW, Canfield RE, Machin KJ, Morgan FJ, Isaacs NW (1994) Crystal structure of human chorionic gonadotropin. Nature 369: 455-461.
2. Talwar GP, Sharma NC, Dubey SK, Salahuddin M, Das C, et al. (1976) Isoimmunization against human chorionic gonadotropin with conjugates of processed $\beta$-subunit of the hormone and tetanus toxoid. Proc Nac Acad Sci 73(1): 218-222.

3. Talwar GP (1976) Entire issue of 14 papers. Contraception 13(2): 129268.

4. Talwar GP, Singh O, Rao LV (1988) An improved immunogen for antihuman chorionic gonadotropin vaccine elicited antibodies reactive with a conformation native to the hormone without cross-reaction with human follicle stimulating hormone and human thyroid stimulating hormone. J Reprod Immunol 14(3): 203-212.

5. Talwar GP, Singh O, Pal R, Chatterjee N, Sahai P, et al. (1994) A vaccine that prevents pregnancy in women. Proc Natl Acad Sci 91(18): 85328536.

6. Singh M, Das SK, Suri S, Singh O, Talwar GP (1998) Regain of fertility and normality of progeny born at below protective threshold antibody titres in women immunized with HSD-TT vaccine. Am J Reprod Immunol 39: 395-398.

7. Purswani S, Talwar GP (2011) Development of a highly immunogenic recombinant candidate vaccine against human chorionic gonadotropin. Vaccine 29(12): 2341-2348.

8. Talwar GP (1999) An immunotherapeutic vaccine for multibacillary leprosy. Int Rev Immunol 18(3): 229-249.

9. Sharma SK, Katoch K, Sarin R, et al (2017) Efficacy and Safety of Mycobacterium indicuspranii as an adjunct therapy in Category II pulmonary tuberculosis in arandomized trial. Scientific Reports 7: 3354 .

10. Singh IG, Mukherjee R, Talwar GP (1991) Resistance to intravenous inoculation of Mycobacterium tuberculosis H37 Rv in mice of different inbred strains following immunization with a leprosy vaccine based on Mycobacterium w. Vaccine 9(1): 10-14. 